\title{
AS ESPÉCIES AMEACADAS E A EDUCACÃO AMBIENTAL: CONHECIMENTO DE ESTUDANTES SOBRE O PAPAGAIO-DE-PEITO-ROXO
}

\author{
ENDANGERED SPECIES AND THE ENVIRONMENTAL EDUCATION: STUDENTS' \\ KNOWLEDGE OF THE VINACEOUS-BREASTED PARROT
} ESPECIES AMEAÇADAS Y LA EDUCAÇÃO AMBIENTAL: CONOCIMIENTO DE
ESTUDIANTES SOBRE EL LORO VINOSO

Nádia Kroth
nadia.kroth@unochapeco.edu.br

Angélica Soligo Cassol angelicaed@unochapeco.edu.br

Eliara Solange Müller eliara@unochapeco.edu.br

REVISTA PEDAGÓGICA

Revista do Programa de Pós-graduação em Educação da Unochapecó | ISSN 1984-1566 Universidade Comunitária da Região de Chapecó | Chapecó-SC, Brasil Como referenciar este artigo: KROTH, N.; CASSOL, A. S.; MÜLLER, E. S. As espécies ameaçadas e a educação ambiental: conhecimento de estudantes sobre o papagaio-de-peito-roxo. Revista Pedagógica, Chapecó, v. 20, n. 44, p. 153-171, mai./ago. DOI: http://dx.doi.org/10.22196/rp.v20i44.4161

RESUMO: As ciências naturais e a da educação ambiental têm um papel primordial na educação científica, especialmente no que tange ao conhecimento sobre as espécies. Para que as ações de educação ambiental sejam efetivas, é fundamental perceber como os indivíduos conhecem e percebem o mundo natural que os rodeia. Visando entender se o contato com os ambientes naturais (com menos interferência do ser humano) interfere no conhecimento de estudantes, investigamos o conhecimento dos mesmos sobre a espécie Amazona vinacea (papagaio-de-peito-roxo), uma espécie ameaçada de extinção. Realizamos o estudo na Região Oeste de Santa Catarina, no sul do Brasil. Aplicamos um questionário para 63 estudantes do $9^{\circ}$ ano do Ensino Fundamental, em seis escolas. Avaliamos o ambiente escolar e questionamos as professoras de Ciências sobre suas aulas em ambientes naturais. Poucos estudantes (20,6\%) conheciam o papagaio-de-peito-roxo, bem como sua ecologia. Desses poucos estudantes que conheciam a espécie, a maioria $(69,2 \%)$ foi classificada com contato mais frequente com ambientes naturais.

Palavras-chave: Amazona vinacea. Ambientes Naturais. Percepção. Educação Ambiental.

ABSTRACT: The natural sciences and environmental education have a major role in scientific education, especially as regards knowledge about species. For environmental education actions to be effective it is essential to understand how individuals know and perceive the natural world that surrounds them. Aiming to understand if the contact with natural environments (with less human interference) interferes with the knowledge of students, we investigate their knowledge about the species Amazona vinacea (vinaceous-breasted Parrot). We conducted the study in western SC, southern
Brazil. We applied a questionnaire with 63 students from the 9th year of elementary school, of six schools. Evaluated the school environment and questioned the teachers of science about their classes in natural environments. Few students $(20,6 \%)$ know about the vinaceous-breasted Parrot as well as its ecology. Of the few students who knew him, most $(69,2 \%)$ were classified with more frequent contact with natural environments.

Keywords: Amazona vinacea. Natural Environments. Perception. Environmental Education.

RESUMEN: Las ciencias naturales y la de la educación ambiental tienen un papel primordial en la educación científica, especialmente en lo que se refiere al conocimiento sobre las especies. Para que las acciones de educación ambiental sean efectivas es fundamental percibir cómo los individuos conocen y perciben el mundo natural que los rodea. Con el fin de entender si el contacto con ambientes naturales (con menos interferencia del ser humano) interfiere en el conocimiento de los estudiantes, investigamos el conocimiento de los mismos sobre la especie Amazona vinacea (loro vinoso). Realizamos el estudio en el oeste de SC, sur de Brasil. Aplicamos un cuestionario para 63 estudiantes del $9^{\circ}$ año de la enseñanza fundamental, de seis escuelas. Evaluamos el ambiente escolar y cuestionamos a las profesoras de ciencias sobre sus clases en ambientes naturales. Pocos estudiantes (20,6\%) conocen el loro vinoso, así como su ecología. De los pocos estudiantes que lo conocían, la mayoría $(69,2 \%)$ fueron clasificados con contacto más frecuente con ambientes naturales.

Palabras clave: Amazona vinacea. Ambientes Naturales. Percepción. Educación Ambiental. 


\section{INTRODUÇÃO}

Para pensar em estratégias e ações de conservação para uma espécie ameaçada de extinção, é fundamental conhecer aspectos relacionados à sua ecologia e biologia (PRIMACK; RODRIGUES, 2001). Esse conhecimento sobre determinada espécie para a população é tão importante quanto para os pesquisadores, principalmente para os indivíduos que vivem no entorno onde está a espécie (MARCATTO, 2002). Neste contexto, trabalhar com os estudantes que vivem em regiões que possuem espécies ameaçadas de extinção pode exercer papel essencial para a conservação da espécie e do seu habitat natural. Para tal ação, torna-se imprescindível entender o que os estudantes compreendem sobre a relação deles com a espécie (COSTA-NETO; PACHECO, 2004). O conjunto de conhecimentos e crenças dos estudantes pode ser utilizado como uma ferramenta de mobilização cognitiva e afetiva, estabelecendo um vínculo entre a realidade do estudante e o conhecimento científico (SOUZA; ALVES; ALVES, 2007). O professor, por meio da educação ambiental e das disciplinas de Ciências e Biologia, deve pensar em ações que estimulem a visão crítica e incentivem os estudantes a serem cidadãos conscientes e dispostos a conservarem a espécie e o habitat natural delas (MARCATTO, 2002; SCRENCI-RIBEIRO; CASTRO, 2010).

A espécie Amazona vinacea (papagaio-de-peito-roxo), da família Psittacidae, ocorre no Brasil, desde o estado da Bahia até o Rio Grande do Sul, no leste do Paraguai e norte da Argentina (SICK, 2001; COCKLE et al., 2007). É uma espécie ameaçada de extinção, na categoria "Em perigo" (CONSEMA, 2011; BIRDLIFE INTERNATIONAL, 2017). Considerando que o papagaio-de-peito-roxo ocorre na Região Oeste de Santa Catarina e, em função das ameaças que sofre - especialmente a captura ilegal -, é essencial que trabalhos de sensibilização para a conservação desta espécie sejam realizados. Para que os trabalhos sejam efetivos, é importante identificar o que os estudantes que moram próximo das áreas de ocorrência da espécie sabem sobre papagaio-de-peito-roxo e se o contato mais frequente ou menos frequente com os ambientes naturais interfere nesse conhecimento. Com base nas discussões de Reigota (2004) e Fonseca e Oliveira (2011), neste trabalho consideramos que ambientes naturais são os recursos naturais, as áreas de vegetação nativa, por exemplo, os fragmentos florestais, bem como ambientes de lazer que proporcionam o contato com os recursos naturais, como fauna e flora, ou seja, ambientes com menos interferência do ser humano. Além disso, consideramos as práticas que enfatizam a relação do ser humano com os ambientes naturais, tais como as atitudes cotidianas de relação naturalista e/ou conservacionista.

Para a efetivação das estratégias que visam à conservação ambiental, é muito importante perceber como os indivíduos conhecem e percebem o mundo natural que 
os rodeia (COSTA-NETO; PACHECO, 2004). Relacionar o conhecimento popular que o estudante traz com o conhecimento científico é um bom aliado para a inserção dos problemas ambientais no cotidiano escolar e, também, nas relações entre os seres humanos e as demais espécies (SOUZA; ALVES; ALVES, 2007; ARAÚJO; KRAEMER; MURTA, 2011). Partir da realidade dos sujeitos, identificando e considerando o conhecimento prévio dos estudantes sobre espécies ameaçadas de extinção, pode ser um passo fundamental para o desenvolvimento da educação ambiental que visa repensar a relação dos indivíduos com a natureza (ambientes naturais) (ARAÚJO; KRAEMER; MURTA, 2011; SOUZA; ALVES; ALVES, 2007).

A escola tem papel fundamental na educação científica do conhecimento sobre as espécies, principalmente por intermédio das ciências naturais e da educação ambiental, que é um tema transversal (SCRENCI-RIBEIRO; CASTRO, 2010). Com o ensino da educação ambiental, que objetiva sensibilizar os indivíduos para a consciência ambiental (REIGOTA, 2004), é possível estimular os estudantes para mudanças de hábito e para uma visão crítica sobre a gravidade dos problemas ambientais e das ameaças à fauna silvestre, por exemplo, o tráfico de animais silvestres (RENCTAS, 2001; MARCATTO, 2002; AGUILAR et al., 2013).

Este estudo objetivou: a) compreender se o contato mais frequente com os ambientes naturais interfere no conhecimento do estudante sobre o papagaio-de-peito-roxo; b) identificar o conhecimento dos estudantes quanto à ocorrência deste papagaio, ecologia, status de conservação e ameaças; e c) identificar os meios de divulgação que mais contribuem para o conhecimento dos estudantes em relação ao papagaio-de-peito-roxo. Nossa hipótese foi que os estudantes que possuem um contato mais frequente com os ambientes naturais têm mais conhecimento sobre a ocorrência, a ecologia, o status de conservação e as ameaças do papagaio-de-peito-roxo, pois esse contato mais frequente proporcionaria maior interesse e conhecimento sobre a fauna regional e, consequentemente, mais consciência em conservá-la.

\section{METODOLOGIA}

\section{As escolas}

O estudo foi realizado em seis escolas, sendo duas no município de São Carlos, duas em Águas de Chapecó e duas em Guatambu, na Região Oeste de Santa Catarina, sul do Brasil. A região, onde as escolas se localizam, é uma região de transição entre duas formações florestais do bioma Mata Atlântica: Floresta Ombrófila Mista - caracterizada pela presença de araucária (Araucaria angustifolia) - e Floresta Estacional Decidual - caracterizada por mais de $50 \%$ dos indivíduos perderem as folhas no período desfavorável. Entre as seis escolas, selecionamos uma do meio 
rural e uma do meio urbano de cada um dos municípios. Estas escolas foram selecionadas para fazer parte da pesquisa por estarem localizadas perto de um dormitório de papagaio-de-peito-roxo ou de áreas onde esta espécie se alimenta e se reproduz. A escolha de uma escola de meio rural e outra de meio urbano foi em função de os estudantes de escolas do meio rural terem mais contato com os ambientes naturais do que estudantes de área urbana (a seguir, escrevemos mais sobre contato com os ambientes naturais). Os três municípios são próximos, com distância de no máximo $24 \mathrm{~km}$ em linha reta, entre eles e entre as escolas estudadas. No município de Guatambu, é conhecido um dormitório coletivo de uma população de papagaio-de-peito-roxo, com aproximadamente 160 indivíduos (ZULIAN; MÜLLER, 2014). A espécie também utiliza as áreas do entorno de Guatambu para alimentação e reprodução.

O município de Águas de Chapecó possui em sua área total $139,13 \mathrm{~km}^{2}$ (IBGE, 2016) e um total de 6.109 habitantes, sendo 3.236 habitantes do meio urbano e 2.873 habitantes do meio rural (IBGE, 2010). O município de São Carlos possui área total de 158,99 km² (IBGE, 2016). Há 10.284 habitantes, sendo 6.899 residentes no meio urbano e 3.385 habitantes residentes no meio rural (IBGE, 2010). O município de Guatambu possui área total de $205.58 \mathrm{Km}^{2}$ (IBGE, 2016), com 4.675 habitantes; dentre eles, 2.926 residentes ao meio rural e 1.749 residentes ao meio urbano (IBGE, 2010).

No município de Guatambu, há a presença de uma Unidade de Conservação Federal, a Floresta Nacional de Chapecó (FLONA), que possui uma área de aproximadamente 1.288 hectares. A paisagem do entorno da Flona (da região) é um mosaico de formações florestais naturais fragmentadas pelo intenso uso agrícola do solo para lavouras anuais, pastagens e silviculturas (ICMBio, 2013).

\section{COLETA DE DADOS}

Considerando as seis escolas, foi aplicado um questionário com 13 questões fechadas (com múltipla escolha) e abertas, para um total de 63 do $9^{\circ}$ ano, último ano do Ensino Fundamental. As escolas do meio rural atendem apenas o Ensino Fundamental; assim, após o $9^{\circ}$ ano, os estudantes precisam mudar de escola para cursar o Ensino Médio.

As quatro primeiras questões do questionário investigaram o contato dos estudantes com os ambientes naturais (onde moram, atividades que realizam, se tinham aulas em contato com os ambientes naturais). As questões cinco e seis investigaram se o estudante conhecia o papagaio-de-peito-roxo e como o havia conhecido. As questões sete, oito e nove investigaram o conhecimento dos estudantes sobre habitat, alimentação e reprodução da espécie. As últimas quatro questões investigaram o conhecimento dos estudantes sobre as ameaças e a conservação da espécie. A coleta de dados foi realizada durante uma aula de Ciências, na sala de aula dos estudantes de cada uma das escolas, no 
segundo semestre do ano de 2016.

Para entendermos melhor o espaço da escola, avaliamos o ambiente escolar a partir de quatro critérios. O primeiro critério foi verificar os ruídos do entorno da escola, oriundos da urbanização, como ruídos de indústrias e tráfego de veículos. O segundo critério foi o nível de construção (nível de urbanização) presente no entorno da escola. O terceiro critério foi a presença de vegetação no pátio e entorno da escola, principalmente a presença de fragmentos florestais. O quarto critério foi a realização de um questionamento para a professora de Ciências da turma do $9^{\circ}$ ano a respeito do desenvolvimento de aulas em ambientes naturais. Todos os estudantes que responderam à pesquisa, por serem menores de idade, tiveram a assinatura do Termo de Consentimento Livre e Esclarecido pelos seus pais e/ou responsáveis, como é previsto pelo comitê de ética.

\section{ANÁLISE DE DADOS}

Para determinar se os estudantes têm contato mais frequente ou menos frequente com os ambientes naturais, foram avaliadas as quatro primeiras questões do questionário. Nestas questões, o estudante com contato mais frequente com os ambientes naturais deveria atender a três dos quatro critérios descritos: residir no meio rural (maior proximidade de ambientes naturais/natureza); incluir entre as quatro atividades que mais desenvolve a realização de trilhas, passeios em ambientes naturais ou visitas a áreas verdes, parques ou praças; informar que tem muito contato com os ambientes naturais e descrever este contato; informar que tem pelo menos, às vezes, aula em ambientes naturais. A partir disso, a análise dos dados sobre o conhecimento do papagaio-de-peito-roxo foi feita, considerando dois grupos, a saber: estudantes com contato mais frequente com os ambientes naturais e estudantes com contato menos frequente com os ambientes naturais. As respostas foram analisadas com base no conhecimento científico já descrito por pesquisadores sobre a espécie (COLLAR, 1997; ABE, 2004; COCKLE et al., 2007; SCHUNCK et al., 2011; ZULIAN; MÜLLER; PETRY 2012; PRESTES et al., 2014; VOLINSKI; MÜLLER, 2014; ZULIAN; MÜLLER, 2014). Por esta pesquisa ser de cunho qualitativo e quantitativo, estabelecemos categorias para uma melhor análise das respostas, de acordo com Deslandes, Gomes e Minayo (1993). Para a análise estatística em relação às respostas obtidas, utilizamos o qui-quadrado, assumindo um nível de significância de 95\%, ou seja, p<0,05.

\section{RESULTADOS E DISCUSSÃO}

\section{Conhecimento do papagaio-de-peito-roxo}

As escolas, quando avaliadas e comparadas, segundo os critérios estabelecidos, apresentam o mesmo perfil, com 
pouco ou nenhum ruído, nível de construção residencial e o entorno com presença de fragmentos florestais. Em relação às aulas em contato com ambientes naturais, todas as professoras citaram que realizam aulas em contato com ambientes naturais sempre que é possível. Na descrição das atividades dessas aulas, citaram a observação de fungos, plantas e animais, o plantio de árvores e visitas a parques.

Dos 63 estudantes entrevistados, 29 (46\%) foram classificados com contato mais frequente e 34 (54\%) com contato menos frequente com ambientes naturais. Do total de estudantes, $50(79,4 \%)$ não conheciam o papagaio-de-peito-roxo e 13 (20,6\%) conheciam. Desses 13 estudantes que conheciam, a maioria $(9=69,2 \%)$ tinha contato mais frequente com ambientes naturais. A televisão foi o principal meio citado pelos estudantes para conhecer o papagaio-de-peito-roxo. Dos estudantes com contato mais frequente com ambientes naturais, a televisão $(8=47 \%)$ e a natureza $(4=23,5 \%)$ foram as alternativas mais citadas. Dos estudantes com contato menos frequente com ambientes naturais, a televisão $(3=37,5 \%)$ e a internet $(3=37,5 \%)$ foram os meios de divulgação mais citados (Gráfico 1).

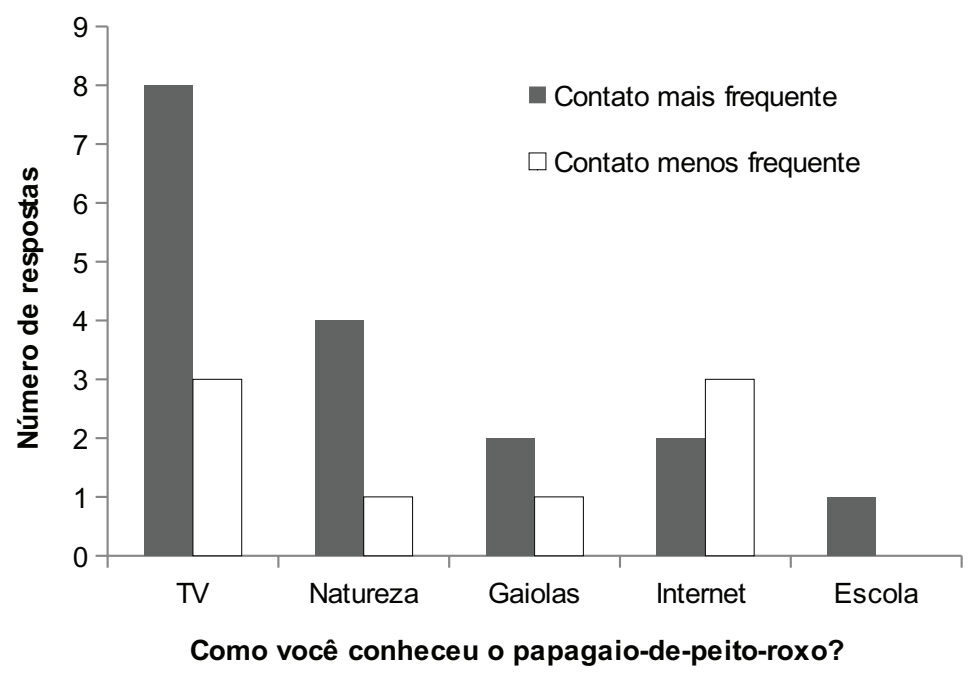

Gráfico 1: Número de respostas dos estudantes com contato mais frequente e menos frequente com ambientes naturais sobre como conheceram o papagaio-de-peito-roxo. Fonte: Elaborado pelos autores (2018).

Uma população de aproximadamente 160 indivíduos de papagaio-de-peito-roxo, utiliza os fragmentos florestais próximos das escolas como áreas para se alimentar, reproduzir e como dormitório (ZULIAN; MÜLLER, 2014). É preocupante constatar que um número baixo de estudantes conhecia a espécie, e que as principais formas de conhecer foram a televisão e a internet. Esse dado revela duas questões preocupantes: as pessoas estão perdendo o hábito de observar a natureza (ambientes naturais) e a escola não considera a natureza (ambientes naturais) do seu entorno como uma ferramenta didática. 
Deve-se ressaltar que a escola tem papel fundamental na educação científica de espécies, principalmente pelo ensino de Ciências e Biologia (BRASIL, 1998); porém, o conhecimento sobre fauna e flora local é pouco explorado pelas escolas (SCHERER; ESSI; PINHEIRO, 2015). As escolas, que foram selecionadas para a aplicação da pesquisa, situam-se próximas de um dormitório coletivo de papagaio-de-peito-roxo e de áreas utilizadas para sua reprodução e alimentação, mas apenas um estudante relatou ter conhecido a espécie através da escola.

Um dos motivos para o pouco conhecimento sobre a biodiversidade pode ser a falta de materiais que divulguem as espécies nativas e levem o conhecimento das universidades para a população de maneira acessível (SCHERER; ESSI; PINHEIRO, 2015). A elaboração de materiais didáticos de divulgação por pesquisadores e professores das universidades ou de centros de pesquisa referentes à biodiversidade regional se faz necessária e possibilita uma aproximação ao conhecimento e, consequentemente, o sentido de pertencimento por parte dos estudantes e da população em geral (DELAZERI; MÜLLER, 2013).

Por outro lado, os dados desta pesquisa destacam a importância dos meios de comunicação na divulgação de assuntos relacionados à ciência. Simultaneamente, percebe-se a grande propagação de meios de comunicação em prol da educação ambiental, por exemplo, com a criação de redes, programas de televisão, sites e blogs na internet relacionados ao tema, que objetivam sensibilizar a população para os problemas decorrentes da degradação ambiental (RODRIGUES; COLESANTI, 2008). Nas divulgações feitas na televisão, valoriza-se a transmissão de informações de caráter científico, como a produção científica e tecnológica regional. Este meio de comunicação pode gerar boas experiências, porque permite, especialmente nas entrevistas, que o cientista reporte o conhecimento que produziu, na universidade ou centros de pesquisa, ao público em geral. Dessa forma, a televisão colabora para que a população compreenda o tema (SOUSA; FERNANDES, 2002).

\section{Conhecimento da biologia do papagaio-de- peito-roxo}

A maioria dos estudantes que possuem contato mais e menos frequente com ambientes naturais não soube responder $(15=50 \% ; 25=64,2 \%$, respectivamente) onde vivem os papagaios-de-peito-roxo. Entre os que souberam responder, a maioria - tanto os com contato mais frequente como os estudantes com contato menos frequente - escolheu a alternativa Florestas da Região Sul do Brasil $(8=26,7 \% ; 5=12,8 \%$, respectivamente). Na questão que trata sobre o local onde o papagaio-de-peito-roxo constrói o ninho, a maioria dos estudantes com contato mais frequente $(19=65,5 \%)$ e menos frequente com ambientes naturais $(30=88,3 \%)$ não soube responder. Entre aqueles que 
souberam responder, a maioria com contato mais frequente $(9=31,1 \%)$ e menos frequente $(3=8,8 \%)$ com ambientes naturais respondeu que o papagaio-de-peito-roxo constrói seu ninho em ocos de árvores velhas e apenas uma minoria dos estudantes com contato mais frequente $(1=3,4 \%)$ e menos frequente $(1=2,9 \%)$ citou que o papagaio-de-peito-roxo constrói o ninho em galhos utilizando gravetos.

$O$ contato mais frequente com ambientes naturais influenciou significativamente nas respostas sobre a alimentação do papagaio-de-peito-roxo $\left(x^{2}=7,17 ; g l=2 ; p=0,02\right)$. Entre os que possuem um contato mais frequente, 15 $(48,4 \%)$ estudantes citaram que a espécie se alimenta de sementes e frutos de diversas árvores, flores e folhas de algumas árvores e raramente insetos; $16(51,6 \%)$ estudantes não souberam responder. Contudo, a maioria dos estudantes que possui contato menos frequente com ambientes naturais não soube responder essa pergunta $(23=65,7 \%)$; oito $(22,9 \%)$ citaram que a espécie se alimenta de sementes e frutos de diversas árvores, flores e folhas de algumas árvores e, raramente, de insetos; quatro $(11,4 \%)$ estudantes citaram que a espécie se alimenta de girassol/alpiste, que é o alimento típico das aves que ficam presas em gaiolas.

Se, por um lado, percebemos que os estudantes não têm contato com o conhecimento relacionado às espécies nativas da região na escola; por outro, notamos que os estudantes com contato mais frequente com ambientes naturais têm maior conhecimento que os estudantes com contato menos frequente sobre a alimentação e a reprodução do papagaio-de-peito-roxo.

O papagaio-de-peito-roxo é uma espécie de ave endêmica da Mata atlântica (SCHUNCK et al., 2011) e está associado às florestas com araucárias (Araucaria angustifolia) na maior parte de sua distribuição geográfica (PRESTES et al., 2014). Em Santa Catarina, os registros e as informações acerca desse papagaio são recentes. Na Região Oeste do estado, tem-se o registro de papagaio-de-peito-roxo para os municípios de São Domingos, Quilombo, Palma Sola, Água Doce e Guatambu (AZEVEDO; GUIZONI-JR, 2008; ZULIAN; MÜLLER; PETRY 2012; LEGAL; CADORIN, 2013; ZULIAN; MÜLLER, 2014; VOLINSKI; MÜLLER, 2014).

O papagaio-de-peito-roxo se alimenta principalmente de sementes, inflorescências, brotos, folhas novas e frutos (SICK, 2001; COLLAR, 1997; ABE, 2004), e há diferenças quanto à dieta da espécie durante as estações e a disponibilidade de alimento (PRESTES et al., 2014). Alguns autores relatam o consumo de invertebrados quando há menor disponibilidade de alimentos vegetais (SICK, 2001; COCKLE et al., 2007). A reprodução do papagaio-de-peito-roxo ocorre de agosto a janeiro. A construção do ninho é feita em ocos (cavidades naturais) de altas árvores com a postura de dois a quatro ovos arredondados, que são incubados por cerca de 25 dias (MORAES, 2010; SCHUNCK et al., 2011). 


\section{Conservação e ameaças ao papagaio-de-peito- roxo}

Tanto para os estudantes com contato mais frequente como aqueles com contato menos frequente com ambientes naturais, a destruição do habitat e o contrabando ilegal $(17=34,7 \%$ e $14=28,6 \% ; 13=26,5 \%$ e $10=20,4 \%$, respectivamente) são os principais motivos para que o papagaio-de-peito-roxo desapareça da natureza. Uma grande parcela dos estudantes com contato menos frequente com ambientes naturais não soube responder $(18=36,7 \%)$ (Gráfico 2).

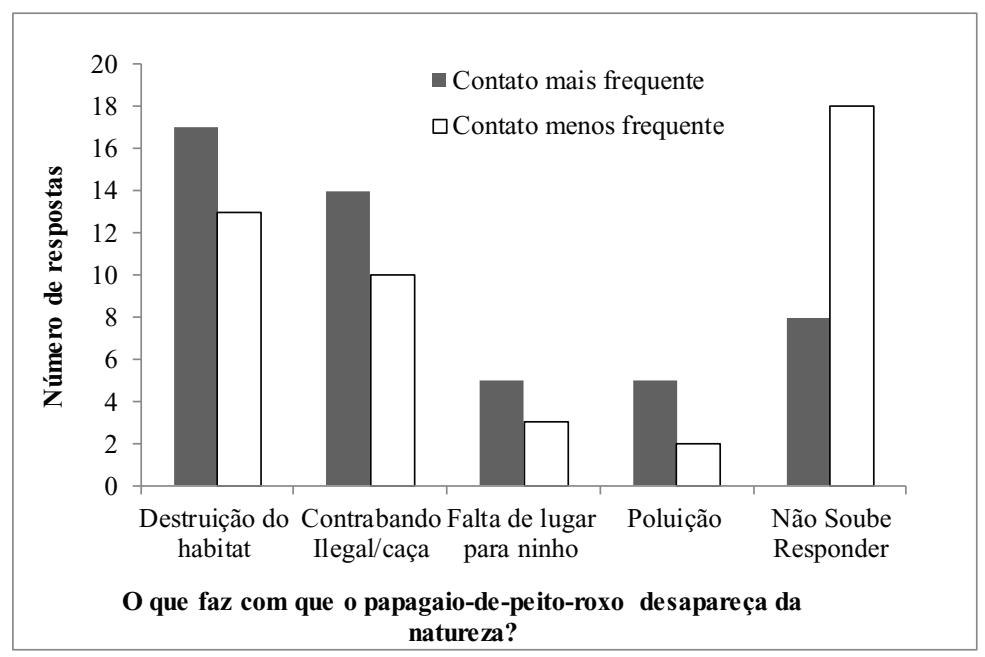

Gráfico 2 - Número de respostas dos estudantes com contato mais frequente e menos frequente com os ambientes naturais sobre o que faz com que o papagaio-de-peito-roxo desapareça da natureza Fonte: Elaborado pelo autor (2018).

A maioria dos estudantes (Tabela 1) com contato mais frequente e menos frequente com ambientes naturais afirmou que o papagaio-de-peito-roxo está ameaçado de extinção ( $16=57,1 \% ; 17=50 \%$, respectivamente), seguido da informação não sei responder $(11=39,3 \% ; 15=44,1 \%$, respectivamente). Das justificativas que foram atribuídas ao fato de a espécie estar ameaçada de extinção, tanto os estudantes com contato mais frequente quanto os com contato menos frequente com ambientes naturais citaram que o contrabando ilegal e a caça são as principais $(9=39,1 \%$; $9=31 \%$ ) causas para a espécie estar ameaçada de extinção.

O papagaio-de-peito-roxo é uma espécie ameaçada de extinção (CONSEMA, 2011; BIRDLIFE INTERNATIONAL, 2017). Os estudantes, em sua maioria, mostraram que conheciam esta informação, e que as principais causas do papagaio-de-peito-roxo estar ameaçado de extinção é a degradação do habitat, a caça e a captura dos filhotes para contrabando ilegal (SCHUNCK et al., 2011; BIRDLIFE INTERNATIONAL, 2017), o que decorre do fato de a espécie apresentar grande beleza e o ser humano exercer uma grande simpatia por ter aves que sejam belas e possam ser domesticadas (CARRILLO, 2003). 
Tabela 1 - Número de respostas e justificativas citadas pelos estudantes do $9^{\circ}$ ano do Ensino Fundamental, quando questionados se o papagaio-de-peito-roxo está ameaçado de extinção

\begin{tabular}{|c|c|c|c|c|}
\hline $\begin{array}{l}\text { Categoria de } \\
\text { contato }\end{array}$ & Alternativas & $\mathrm{N}^{\circ} \mathrm{e} \%$ & Categoria das justificativas & No e \% \\
\hline \multirow{7}{*}{$\begin{array}{l}\text { Contato mais } \\
\text { frequente }\end{array}$} & \multirow{5}{*}{ Sim } & \multirow{5}{*}{$16=57,1 \%$} & Contrabando ilegal/caça & $9=39,1 \%$ \\
\hline & & & Espécie rara & $5=21,7 \%$ \\
\hline & & & Desmatamentos & $4=17,4 \%$ \\
\hline & & & Beleza & $3=13,1 \%$ \\
\hline & & & Não soube responder & $2=8,7 \%$ \\
\hline & Não & $1=3,6 \%$ & Ocorre próximo a sua casa & $1=100 \%$ \\
\hline & Não soube responder & $11=39,3 \%$ & & \\
\hline \multirow{9}{*}{$\begin{array}{c}\text { Contato } \\
\text { menos } \\
\text { frequente }\end{array}$} & \multirow{6}{*}{ Sim } & \multirow{6}{*}{$17=50 \%$} & Contrabando ilegal/caça & $6=31,5 \%$ \\
\hline & & & Espécie rara & $3=15,8 \%$ \\
\hline & & & Desmatamentos & $3=15,8 \%$ \\
\hline & & & Professor comentou & $1=5,3 \%$ \\
\hline & & & Beleza & $1=5,3 \%$ \\
\hline & & & Não soube responder & $5=26,3 \%$ \\
\hline & \multirow{2}{*}{ Não } & \multirow{2}{*}{$2=5,9 \%$} & Cuidado pelo ser humano na natureza & $1=50 \%$ \\
\hline & & & Não soube responder & $1=50 \%$ \\
\hline & Não soube responder & $15=44,1 \%$ & & \\
\hline
\end{tabular}

Fonte: Elaborada pelo autor (2018).

O contato mais frequente com os ambientes naturais influencia o conhecimento sobre a espécie, pois, como estudos já apontam, os estudantes apresentam uma percepção e atitudes de conservação fortemente ligadas ao meio em que vivem e pelo possível contato com a natureza (ambientes naturais) (DELAZERI; MÜLLER, 2013; BORDIN et al., 2016; SCHERER; ESSI; PINHEIRO, 2015). A falta de contato com os ambientes naturais e a crescente utilização de tecnologias no dia a dia dos jovens, pode fazer com que o conhecimento sobre a biodiversidade nativa não seja adquirido (SCHERER; ESSI; PINHEIRO, 2015).

Estudantes que possuem contato mais frequente $(25=86,2 \%)$ e menos frequente $(26=81,3 \%)$ com ambientes naturais citaram que devemos proteger o papagaio-de-peito-roxo (Tabela 2). Entre as justificativas dos estudantes com o contato mais frequente com ambientes naturais, a justificativa com maior número de respostas $(9=31 \%)$ foi de que devemos proteger a espécie porque ela está ameaçada de extinção, seguida da alternativa porque todos os animais devem ser protegidos $(5=17,2 \%)$ e por sua beleza $(4=13,8 \%)$. Entre os estudantes que possuem um contato menos frequente com ambientes naturais, a justificativa mais citada foi que devemos proteger o papagaio-de-peito-roxo porque devemos proteger todos os animais $(10=32,3 \%)$, seguida da justificativa de estar ameaçado de extinção $(7=22,6 \%)$, por sua beleza $(4=12,9 \%)$ e para as futuras gerações poderem conhecê-lo $(4=12,9 \%)$. 
Tabela 2 - Número de respostas e justificativas citadas pelos estudantes do $9^{\circ}$ ano do Ensino Fundamental, quando questionados se devemos proteger o papagaio-de-peito-roxo?

\begin{tabular}{|c|c|c|c|c|}
\hline $\begin{array}{l}\text { Categoria de } \\
\text { contato }\end{array}$ & Alternativas & No e \% & Justificativas & No e \% \\
\hline \multirow{11}{*}{$\begin{array}{l}\text { Contato mais } \\
\text { frequente }\end{array}$} & \multirow{9}{*}{ Sim } & \multirow{9}{*}{$25=86,2 \%$} & Ameaçado & $9=31 \%$ \\
\hline & & & Proteção de todos os animais & $5=17,2 \%$ \\
\hline & & & Beleza do animal & $4=13,8 \%$ \\
\hline & & & Benefício para a Natureza & $2=6,9 \%$ \\
\hline & & & Bonito ver solto & $2=6,9 \%$ \\
\hline & & & Conhecimento das futuras gerações & $2=6,9 \%$ \\
\hline & & & Equilíbrio cadeia alimentar & $2=6,9 \%$ \\
\hline & & & Reprodução & $1=3,5 \%$ \\
\hline & & & Não soube responder & $2=6,9 \%$ \\
\hline & Não & $1=3,5 \%$ & Não soube responder & $1=100 \%$ \\
\hline & Não soube responder & $3=10,3 \%$ & & \\
\hline \multirow{10}{*}{$\begin{array}{c}\text { Contato } \\
\text { menos } \\
\text { frequente }\end{array}$} & \multirow{9}{*}{ Sim } & \multirow{9}{*}{$26=81,3 \%$} & Proteção de todos os animais & $10=32,3 \%$ \\
\hline & & & Ameaçado & $7=22,6 \%$ \\
\hline & & & Beleza do animal & $4=12,9 \%$ \\
\hline & & & Conhecimento das futuras gerações & $4=12,9 \%$ \\
\hline & & & Benefício para a Natureza & $2=6,5 \%$ \\
\hline & & & Bonito ver solto & $1=3,2 \%$ \\
\hline & & & Para reproduzir & $1=3,2 \%$ \\
\hline & & & Equilíbrio cadeia alimentar & $1=3,2 \%$ \\
\hline & & & Não soube responder & $1=3,2 \%$ \\
\hline & Não soube responder & $6=18,7 \%$ & & \\
\hline
\end{tabular}

Fonte: Elaborada pelo autor (2018).

Quando os estudantes foram questionados se tivessem a oportunidade de ter o papagaio-de-peito-roxo como animal de estimação, a maioria dos estudantes com contato mais frequente $(11=64,7 \%)$ e menos frequente $(22=64,7 \%)$ com ambientes naturais respondeu que não e a justificativa mais citada é que devemos manter o papagaio-de-peito-roxo no seu habitat natural. Os estudantes com contato mais e menos frequente que assinalaram que o teriam como animal de estimação justificaram que o principal motivo seria por ser um animal de grande beleza ou por gostar de animais, principalmente "pássaros" (Tabela 3).

A percepção da importância de proteger o papagaio-de-peito-roxo pelos estudantes é outro ponto que chama atenção. A maioria dos estudantes relatou que todos os animais devem ser protegidos e cada qual possui sua importância para o meio em que está inserido, bem como mostrou a preocupação de protegê-lo por ser um animal bonito e que deveria ser protegido para que futuras gerações o possam conhecer. Os estudantes mostram-se conscientes em relação à importância de proteger a espécie por diversos fatores. A consciência pode ser entendida como uma mudança de comportamento, tanto de atividades quanto em aspectos da vida, dos indivíduos e da sociedade em relação ao meio ambiente a partir do saber ambiental. 
Tabela 3 - Número de respostas e justificativas citadas pelos estudantes do $9^{\circ}$ ano do Ensino Fundamental, quando questionados se tivessem a oportunidade de ter um papagaio-de-peito-roxo como animal de estimação, o teriam.

\begin{tabular}{|c|c|c|c|c|}
\hline $\begin{array}{l}\text { Categoria de } \\
\text { contato }\end{array}$ & Alternativas & $\mathbf{N}^{\circ} \mathbf{e} \%$ & Justificativas & $\mathbf{N}^{\circ} \mathbf{e} \%$ \\
\hline \multirow{12}{*}{$\begin{array}{l}\text { Contato mais } \\
\text { frequente }\end{array}$} & \multirow{6}{*}{ Sim } & \multirow{6}{*}{$14=48,3 \%$} & Beleza & $6=37,5 \%$ \\
\hline & & & Gosto por animais/ "pássaros" & $4=25 \%$ \\
\hline & & & Proteção & $3=18,6 \%$ \\
\hline & & & Alto valor comercial & $1=6,3 \%$ \\
\hline & & & Ensinar a falar & $1=6,3 \%$ \\
\hline & & & Porque seria legal & $1=6,3 \%$ \\
\hline & \multirow{6}{*}{ Não } & \multirow{6}{*}{$15=51,7 \%$} & Manter em habitat natural & $11=64,7 \%$ \\
\hline & & & Não conhece & $2=11,7 \%$ \\
\hline & & & Estar em extinção & $1=5,9 \%$ \\
\hline & & & É crime & $1=5,9 \%$ \\
\hline & & & Não justificou & $1=5,9 \%$ \\
\hline & & & Porque tem aviário & $1=5,9 \%$ \\
\hline \multirow{12}{*}{$\begin{array}{l}\text { Contato menos } \\
\text { frequente }\end{array}$} & \multirow{5}{*}{ Sim } & \multirow{5}{*}{$9=26,5 \%$} & Gosto por animais/ "pássaros" & $2=22,2 \%$ \\
\hline & & & Beleza & $4=44,5 \%$ \\
\hline & & & Proteção & $1=11,1 \%$ \\
\hline & & & Já teve & $1=11,1 \%$ \\
\hline & & & Porque seria legal & $1=11,1 \%$ \\
\hline & \multirow{6}{*}{ Não } & \multirow{6}{*}{$22=64,7 \%$} & Manter em habitat natural & $10=50 \%$ \\
\hline & & & Não saberia cuidar & $4=20 \%$ \\
\hline & & & Dão muito trabalho & $2=10 \%$ \\
\hline & & & Não justificou & $2=10 \%$ \\
\hline & & & Estar em extinção & $1=5 \%$ \\
\hline & & & Não conhece & $1=5 \%$ \\
\hline & Não soube responder & $3=8,8 \%$ & & \\
\hline
\end{tabular}

Fonte: Elaborada pelo autor (2018).

A tomada de consciência muitas vezes se torna superficial em relação a determinados assuntos, pois uma grande quantidade de estudantes respondeu que teriam o papagaio-de-peito-roxo como animal de estimação. E as justificativas foram que os estudantes o teriam principalmente por gostarem de animais, pelo fato de a espécie apresentar beleza, o que gera simpatia aos seres humanos, e porque o papagaio-de-peito-roxo apresenta alto valor comercial. As justificativas dos estudantes que responderam que não teriam um papagaio como animal de estimação mostram que existe consciência por boa parte destes estudantes. Estes justificaram que não o teriam pela importância de manter essa ave em habitat natural, por ela estar ameaçada de extinção, preferirem vê-la livre ou por não saberem como cuidá-la adequadamente, caso a mantivessem em cativeiro. $\mathrm{O}$ apreço por ter animais domesticados é historicamente carregado pelo ser humano em termos culturais e são numerosos os exemplos de criação ou manutenção de animais silvestres em cativeiro na maioria das culturas humanas, tanto antigas quanto modernas (SILVEIRA, 2013). O hábito cultural de manter aves em cativeiro está entre as principais causas que levam as espécies 
deste grupo à ameaça de extinção e, apesar de os estudantes mostrarem preocupação de proteger a espécie, possuir os animais ainda se apresenta fortemente ligado à cultura.

Visando instigar a preocupação dos estudantes em manterem as aves no habitat natural, algumas experiências interdisciplinares adotadas e baseadas na ornitologia são aplicadas na educação ambiental. Alguns exemplos destas experiências são jogos, brincadeiras, observação e identificação de aves em ambientes naturais auxiliados por guias de identificação, palestra com uso de painéis ilustrativos, e passeio didático em zoológicos. Atividades estas que exploram os benefícios da observação das aves na formação do sujeito, em uma concepção integradora, consciente e humanista. A observação agrega o fator sensibilizador ao proporcionar o contato direto dos estudantes com as aves, muitas vezes em seu ambiente natural, fazendo uma relação entre a conservação das aves e dos ambientes naturais a elas associados (COSTA, 2007).

Dessa forma, um tema muito importante que deve ser trabalhado através da educação ambiental é o combate ao tráfico de animais silvestres (RENCTAS, 2001; MAGALHÃES, 2002) aliado à fiscalização (RENCTAS, 2001), buscando esclarecer para a sociedade a importância da conservação da fauna silvestre (MAGALHÃES, 2002). Uma das formas é o desenvolvimento de campanhas de educação ambiental contra o tráfico por meio de materiais informativos, como fôlderes, vídeos e cartazes (RENCTAS, 2001). Magalhães (2002) afirma que a utilização de psitacídeos em campanhas educativas seria uma das alternativas, pelo fato de os psitacídeos serem os animais mais encontrados em cativeiros e utilizados no tráfico ilegal (CALOURO; LOPES, 2000).

A educação ambiental objetivando conservação de espécies nativas da região apresenta-se essencial, de forma articulada, em todos os níveis e modalidades do processo educativo. Sua importância está relacionada a promover mudanças de hábitos e uma visão crítica que conduz à conscientização do estudante (AGUILAR et al., 2013). Ressaltamos que a educação ambiental é uma ferramenta para a conservação e a importância do conhecimento prévio dos estudantes para a efetivação das ações voltadas à conservação ambiental. Uma das alternativas para a conservação de uma espécie nativa da região é torná-la uma espécie bandeira. Para isso, é necessário o conhecimento de alguns fatores relacionados à espécie, como as características ecológicas e o potencial de chamar a atenção e receber apoio do público. O primeiro fator se refere à importância que a espécie possui para o seu ambiente; o segundo fator trata da simpatia que algumas espécies exercem na raça humana, como é o caso de aves, em especial os papagaios (CARRILLO, 2003).

Não se protege o que não se conhece; logo, é preciso conhecer para conservar a fauna e flora nativas (SCHERER; ESSI; PINHEIRO, 2015). O saber prévio do 
estudante é muitas vezes errôneo sobre determinados assuntos; mas, todo processo de aprendizagem começa com o conhecimento mais simples para que o mais complexo seja construído.

Diante disso, ressaltamos a importância de saber o conhecimento prévio dos estudantes sobre os conteúdos antes de estes serem trabalhados na sala de aula em ações de educação ambiental (OLIVEIRA; SILVA-SANTANA, 2015). A educação ambiental conservacionista (REIGOTA, 2004) precisa fazer parte do cotidiano escolar, levando os estudantes a refletirem sobre as questões atuais. A educação ambiental pode não somente promover a análise de temas que tragam, de forma interdisciplinar, o meio natural e as relações sociais, como também contribuir para formar cidadãos conscientes, capazes de decidirem e atuarem na realidade socioambiental, comprometendo-se com a vida e o bem-estar individual e da sociedade (MEDEIROS et al., 2011).

\section{CONSIDERAÇÕES FINAIS}

Poucos estudantes questionados nesta pesquisa (20,6\%) conheciam o papagaio-de-peito-roxo, bem como sua ecologia. Entre esses poucos estudantes que conheciam essa ave, a maioria $(69,2 \%)$ foi classificada com contato mais frequente com ambientes naturais. Um ponto importante é que os principais meios de divulgação que contribuíram para o conhecimento dos estudantes sobre essa espécie de papagaio foram a televisão e a internet. Isso demonstra que as escolas desta região possivelmente não abordaram de maneira efetiva essa espécie ameaçada de extinção (Amazona vinacea) que ocorre no entorno das escolas. Por isso, consideramos importante incluir este assunto no planejamento dos professores, a fim de contribuir para o conhecimento e conservação da espécie.

Apesar de os estudantes demonstrarem ter consciência da importância de protegerem e conservarem a espécie, a influência cultural de manter aves em gaiolas e domesticá-las ainda é um aspecto muito presente no cotidiano. Esta influência cultural faz com que os estudantes tenham o apreço em ter o papagaio-de-peito-roxo como animal de estimação. Como os estudantes possuem um papel importante para o futuro, por meio da educação ambiental é possível envolvê-los e torná-los protagonistas em ações de conservação da natureza.

\section{REFERÊNCIAS}

ABE, Lígia Mieko. Caracterização do habitat do papagaio-de-peito-roxo Amazona vinacea (kuhl, 1820) no município de Tunas do Paraná, região metropolitana de Curitiba, Paraná. 2004. 98 f. Dissertação (Mestrado) - Universidade Federal do Paraná, Curitiba, 2004. Disponível em: <http://acervodigital.ufpr. 
br/bitstream/handle/1884/27865/R\%20\%20D\%20\%20 LIGIA\%20MIEKO\%20ABE.pdf?sequence=1>. Acesso em: 18 nov. 2016.

AGUILAR, Thaís Maya; REIS, Jéssica Elias; CASTILLO, Vivian Moreno; RIBEIRO, Flávia; GOMES, Vanessa Matos; LINS, Lívia Vanucci. Oficinas de educação ambiental do projeto Pato Aqui, Água Acola em escolas de São Roque de Minas, Minas Gerais, Brasil. E-Scientia, v. 6, n. 1, p. 16-35, 2013. Disponível em: <www.unibh.br/revistas/escientia>. Acesso em: 18 nov. 2016.

ARAÚJO, Ramon Teixeira Nascimento de; KRAEMER, Bruno Machado; MURTA, Paula Fernanda Oliveira. Percepções ambientais e concepções de estudantes do Ensino Fundamental de Belo Horizonte/MG sobre tubarões. E-Scientia, v. 4, n. 1, p. 69-79, 2011. Disponível em: <www.unibh.br/revistas/escientia>. Acesso em: 18 maio 2016.

AZEVEDO, Marco Antônio Guimarães; GHIZONI-JR, Ivo Rohling. Aves. In: CHEREM, Jorge José; KAMMERS, Marcelo (Org.). A fauna das áreas de influência da Usina Hidrelértica Quebra-Queixo. Erechim: Habilis, 2008. p. 131-150.

BIRDLIFE INTERNATIONAL. Amazona vinacea. The IUCN Red List of Threatened Species 2017: e.T22686374A118954406, 2017. Disponível em: <http://dx.doi.org/10.2305/IUCN.UK.2017-3.RLTS. T22686374A118954406.en>. Acesso em: 6 ago. 2018.

BORDIN, Kauane Maiara; ZANOTELLI, Patricia; VENDRUSCOLO, Giovana. Secretti; CONFORTIN, Ana Cristina; STUANI, G. M. O contato com o ambiente influencia nas atitudes de conservação ambiental entre estudantes?. In: VENDRUSCULO, Giovana. Secretti; CONFORTIN, Ana Cristina; DICKMANN, Ivo (Orgs.).. Percepção de meio ambiente: o que pensam as pessoas sobre seu entorno?. 1. ed. São Paulo: Ação Cultural, 2016. p. 25-48.

BRASIL. Secretaria de Educação Fundamental. Parâmetros curriculares nacionais: Ciências Naturais. Brasília: MEC, 1998.

CALOURO, Arando Muniz; LOPES, Daniela Christiane de Souza. Habitantes 'clandestinos' de Rio Branco. Ciência Hoje, v. 27, n. 160, p. 54-56, 2000. Disponível em: $<$ https://www.researchgate.net/publication/261026995_ Habitantes_clandestinos_de_Rio_Branco $>$. Acesso em: 19 maio 2016.

CARRILlO, Andrea Caro. Educação Ambiental para a Conservação do Papagaio-da-Cara-Roxa (Amazona brasiliensis), no Estado do Paraná 
- uma experiência na escola. 2003. 192 f. Dissertação (Mestrado em Engenharia Florestal, Área de Concentração em Conservação da Natureza, do Setor de Ciências Agrárias), Universidade Federal do Paraná, Curitiba, 2003. Disponível em: <http://acervodigital.ufpr.br/bitstream/ handle/1884/26105/D\%20\%20CARRILLO\%2c\%20 ANDREA\%20CARO.pdf? sequence $=1 \&$ is Allowed $=y>$. Acesso em: 18 maio 2017.

COCKLE, Kristina; CAPUZZI, Gabriel; BODRATI, Alejandro; CLAY, Rob; CASTILLO, Hugo Del;VELÁZQUEZ, Myriam; ARETA, Juan Ignacio; FARIÑA, Nestor; FARIÑA, Rodrigo. Distribution, abundance, and conservation of Vinaceous Amazons (Amazona vinacea) in Argentina and Paraguay. Journal of Field Ornithology, v. 78, n. 1, p. 21-39, 2007.

COLLAR, N. J. Familia Psittacidae (Parrots). In: DEL HOYO, Josep.; ELLIOT, Andrew; SARGATAL, Jordi (Ed.). Handbook of the birds of the World. Barcelona: Lynx Edicions, 1997. p. 280-447.

CONSEMA, Conselho Estadual do Meio Ambiente. Lista Oficial de Espécies da Fauna Ameaçadas de Extinção no Estado de Santa Catarina. 2011. Disponível em: <http://www.slideshare.net/carcara7/ lista-especies-ameacadas-santa-catarina $>$. Acesso em: 13 maio 2016.

COSTA, Ronaldo Gonçalves de Andrade. Observação de aves como ferramenta didática para educação ambiental. Revista Didática Sistêmica, v. 6, p. 33-44, 2007. Disponível em: https://www.seer.furg.br/redsis/article/ view/1239/534. Acesso em: 18 maio 2016.

COSTA-NETO, Eraldo Medeiros; PACHECO, Josué Marques. A construção do domínio etnozoológico "inseto" pelos moradores do povoado de Pedra Branca, Santa Terezinha, Estado da Bahia. Acta Scientiarum. Biological Sciences, v. 26, n. 1, p. 81-90, 2004. Disponível em: <http://periodicos.uem.br/ojs/index. php/ActaSciBiolSci/article/view/1662/1004>. Acesso em: 18 maio 2016.

DELAZERI, Francieli; MÜLLER, Eliar Solange. Compreensão de estudantes finalistas do Ensino Fundamental sobre animais nativos e exóticos. 2013. 56 f. Trabalho de Conclusão do Curso (Curso de Ciências Biológicas), Universidade Comunitária da Região de Chapecó, Chapecó, 2013. Disponível em: <http:// www5.unochapeco.edu.br/pergamum/biblioteca/php/ imagens/oooobo/oooobob1.pdf >. Acesso em: 25 nov. 2016.

DESLANDES, Suely Ferreira; GOMES, Romeu; MINAYO, Maria Cecília de Souza. Pesquisa social: teoria, método e criatividade. Petrópolis: Vozes, 1993. 
FONSECA, Fabíola Simões Rodrigues da; OLIVEIRA, Leandro Gonçalves. Concepções de meio ambiente dos educadores ambientais do Zoológico de Goiânia: implicações nas atividades e contribuições para a formação do sujeito ecológico?. Educar em Revista, n. 41, p. 231-246, 2011. http://www.redalyc.org/articulo. oa?id=155021076015. Acesso em: 25 nov. 2016.

IBGE, Instituto Brasileiro de Geografia e Estatística. População do último Censo. 2010. Disponível em: <http://cidades.ibge.gov.br/xtras/perfil.php?lang=\&co dmun $=420050 \&$ search $=$ santa-catarina $>$. Acesso em: 19 maio 2016.

Manual técnico da vegetação brasileira: sistema fitogeográfico, inventário das formações florestais e campestres, técnicas e manejo de coleções botânicas, procedimentos para mapeamentos. Rio de janeiro: IBGE - Diretoria de Geociências, 2012. (Manuais Técnicos de Geociências, 1).

ICMBIO, Instituto Chico Mendes de Conservação da Biodiversidade. Plano de Manejo da Floresta Nacional de Chapecó. Volume I - Diagnóstico. Florianópolis: ICMBio, 2013.

LEGAL, Evair; CADORIN, Tiago João. Avifauna em remanescentes de Floresta Ombrófila Mista no Estado de Santa Catarina, sul do Brasil. In: CONGRESSO BRASILEIRO DE ORNITOLOGIA, 20., 2013, Passo Fundo, RS. Anais eletrônicos... Passo Fundo: SBO/UPF, 2013. Disponível em: <http://editora.upf.br/index.php/ebooks-topo/43-biologia-area-do-conhecimento/69-anaisdo-congresso-brasileiro-de-ornitologia $>$. Acesso em: 12 out. 2016.

MAGAlHÃES, Janaina Silvestre. Tráfico de animais silvestres no Brasil. 2002. $56 \mathrm{f}$. Monografia (Curso de Ciências Biológicas) - Centro Universitário de Brasília, Brasília, 2002. Disponível em: <http://repositorio. uniceub.br/bitstream/123456789/2431/2/9760705.pdf > . Acesso em: 27 nov. 2016.

MARCATTO, Celso. Educação ambiental: conceitos e princípios. Belo Horizonte: FEAM, 2002. Disponível em: <http://www.feam.br/images/stories/arquivos/ Educacao_Ambiental_Conceitos_Principios.pdf $>$. Acesso em: 16 maio 2016.

MEDEIROS, Aurélia Barbosa; MENDONÇA, Maria José da Silva Lemes; SOUSA, Gláucia Lourenço de; OLIVEIRA, Itamar Pereira de. Importância da educação ambiental na escola nas séries iniciais. Revista Faculdade Montes Belos, v. 4, n. 1, p. 1-17, 2011. Disponível em: <http://www. terrabrasilis.org.br/ecotecadigital/pdf/a-importancia-da- 
educacao-ambiental-na-escola-nas-series-iniciais.pdf $>$. Acesso em: 16 maio 2016.

MORAES, Larissa Lacerda. A ave da vez: Amazona vinacea (papagaio-de-peito-roxo). Bicho da vez, n. 24, 2010. Disponível em: <www.museudezoologia.ufv.br>. Acesso em: 16 maio 2016.

OLIVEIRA, Pâmela Saionara de Freitas; SILVA-SANTANA, Cristiana de Cerqueira. Percepção de alunos do sétimo ano sobre os anfíbios em uma escola municipal no Semiárido Baiano, Brasil.Revista GestãoUniversitária,v.4,p.1-12, 2015. Disponível em: <http://www.gestaouniversitaria. com.br/system/scientificarticles/files/ooo/ooo/123/ original/ERCEP\%C3\%87\%C3\%83O_DE_ALUNOS_ SOBRE_OS_ANF\%C3\%8DBIOS_.pdf?1447193680>. Acesso em: 25 nov. 2016.

PRESTES, Nêmora Pauletti; MARTINEZ, Jaime; KILPP, Jonas Claudiomar; BATISTELA, Thalita; TURKIEVICZ, Andréia; REZENDE, Élinton; GABOARDI, Viviane Telles Rodrigues. Ecologia e conservação de Amazona vinacea em áreas simpátricas com Amazona pretrei. Ornithologia, v. 6, n. 2, p. 109-120, 2014. Disponível em: <cemave.net/publicacoes/index.php/ornithologia/ article/download/192/135>. Acesso em: 18 maio 2016.

PRIMACK, Richard B.; RODRIGUES, Efram. Biologia da conservação. Londrina: Planta, 2001, 328 p.

REIGOTA, Marcos. Meio ambiente e representação social. São Paulo: Cortez, 2004, 88p.

RENCTAS. $1^{\circ}$ Relatório Nacional sobre o Tráfico de Fauna Silvestre. 2001. Disponível em: <http:// www.renctas.org.br/wp-content/uploads/2014/o2/REL_ RENCTAS_pt_final.pdf $>$. Acesso em: 19 maio 2016.

SCRENCI-RIBEIRO, Rafaela; CASTRO, Edward Bertholine de. O zoológico da UFMT como ferramenta para o ensino da biodiversidade. Revista Eletrônica do Mestrado em Educação Ambiental, v. 24, p. 204-218, 2010. Disponível em: https://www.seer.furg.br/remea/article/ download/3893/2323>. Acesso em: 18 maio 2016.

RODRIGUES, Gelze Serrat de Souza Campos; COLESANTI, Marlene T. de Muno. Educação ambiental e as novas tecnologias de informação e comunicação. Sociedade \& Natureza, v. 20, n. 1, p. 51-66, 2008. Disponível em: <http://dx.doi.org/10.1590/S198245132008000100003>. Acesso em: 25 nov. 2016.

SCHERER, Hulia Juana, ESSI, Liliana; PINHEIRO, Damaris Kirsch. O conhecimento da Biodiversidade: um estudo de caso com estudantes de graduação de 
uma universidade brasileira. Revista Monografias Ambientais, v. 14, n. 2, p. 49-58, 2015.

SCHUNCK, Fabio; SOMENZARI, Marina; LUGARINI, Camile; SOARES, Elisiário Strike. Plano de Ação Nacional para a Conservação dos Papagaios da Mata Atlântica. Brasília: ICMBio/MMA, 2011. Disponível em: <http://www.icmbio.gov.br/portal/images/stories/ docs-plano-de-acao/pan-papagaios/pan-papagaios.pdf $>$. Acesso em: 18 maio 2016.

SICK, Helmut. Ornitologia brasileira. Rio de Janeiro: Nova Fronteira, 2001.

SILVEIRA, Luís Fábio. Pela criação comercial de aves brasileiras. Cães e Cia, n. 408, p. 48-50, 2013. Disponível em: <http://www.ib.usp.br/ lfsilveira/pdf/a_2013_ ceccriacao.pdf $>$. Acesso em: 25 nov. 2016.

SOUSA, Cidoval Moraes de; FERNANDES, Francisco Assis Martins. Mídia e meio ambiente: limites e possibilidades. Revista Ciências Humanas, Taubaté, v. 8, n. 2, p. 159167, 2002.

SOUZA, Renata Manzi de; ALVES, Ângelo Giuseppe Chaves Alves; ALVES, Marcos Souto. Conhecimento sobre o molusco gigante africano Achatina fulica entre estudantes de uma escola pública na Região Metropolitana do Recife. Biotemas, Florianópolis, v. 20, n. 1, p. 81-89, 2007.

VOLINSKI, Andressa Samara; MÜLLER, Eliara Solange. Etograma de Amazona vinacea (Kuhl, 1820) em ambiente natural. 2014. $30 \mathrm{f}$. Trabalho de Conclusão de Curso (Ciências Biológicas) - Universidade Comunitária da Região de Chapecó, Chapecó, 2014. Disponível em: $<$ http://fleming.unochapeco.edu.br:8080/pergamumweb/ vinculos/ooooB5/ooooB55C.PDF>. Acesso em: 16 maio 2016.

ZULIAN, Viviane; MÜLLER, Eliara Solange. Variação populacional de Amazona vinacea (KUHL, 1820) em um dormitório no sul do Brasil. 2014. 28 f. Trabalho de Conclusão de Curso (Ciências Biológicas) Universidade Comunitária da Região de Chapecó, Chapecó, 2014. Disponível em: <http://www5.unochapeco.edu.br/ pergamum/biblioteca/php/imagens/ooooB4/ooooB4F4. pdf. Acesso em: 16 maio 2016.

ZULIAN, Viviane; MÜLLER, Eliara Solange; PETRY, Maria Virgínia.Tamanho populacional e caracterização das áreas utilizadas por Amazona vinacea (papagaio-de-peitoroxo) como dormitório. In: CONGRESSO BRASILEIRO DE ORNITOLOGIA, 19., 4-7 nov. 2012, Maceió. Anais eletrônicos... Maceió: SBO/UFAL, 2012. Disponível em: <http://editora.upf.br/index.php/e-books-topo/43biologia-area-do-conhecimento/69-anais-do-congressobrasileiro-de-ornitologia>. Acesso em: 12 out. 2016. 